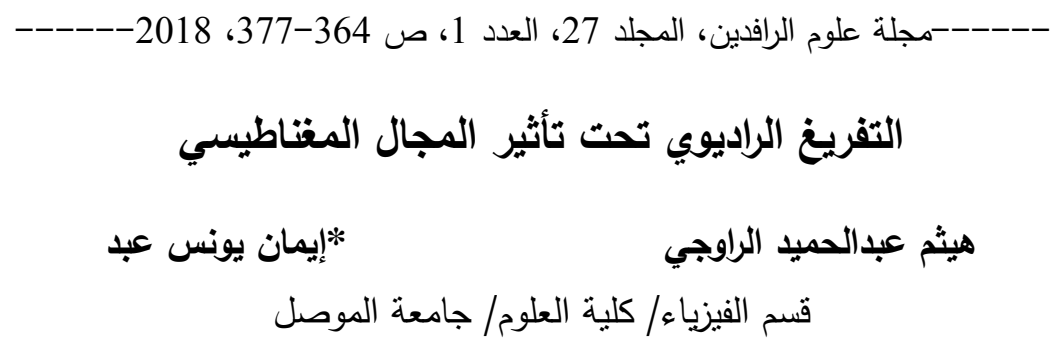

*E-mail: imanyounis633@ gmail.com

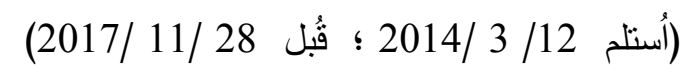

\begin{abstract}
الملخص

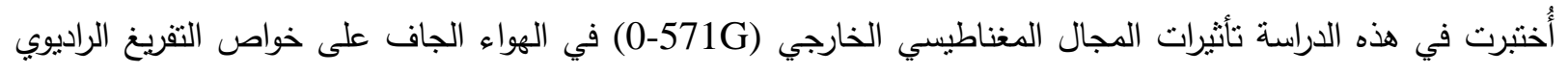

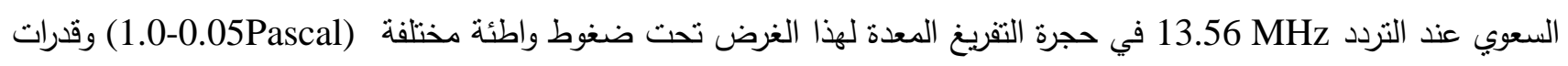

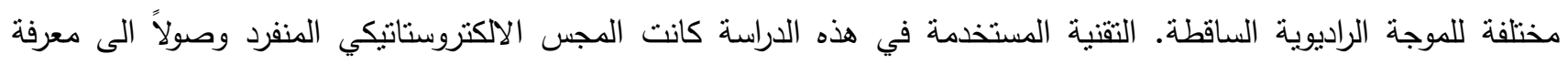

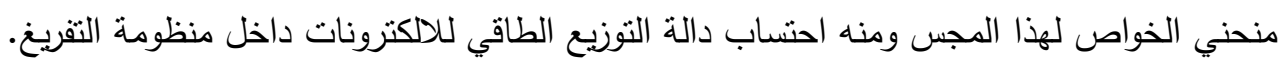
الكلمات الدالة: المجال المغناطيسي، التفريغ الراديوي السعوي، دالة التوزيع الطاقي، بلازما التفريغ التوهجي.
\end{abstract}

\title{
Radio Frequency Discharge Under the Effect of Magnetic Field
}

\author{
Haitham A. AL-Rawachy \\ Eman Y. Abed \\ Department of Physics /College of Science/ University of Mosul
}

\begin{abstract}
In this study We tested the effects of external magnetic field $(0-571 \mathrm{G})$ in dry air on the characteristic of capacitive radio discharge at $13.56 \mathrm{MHz}$ in a discharge chamber prepared for this purpose under different low pressure (1.0-0.05 Pascal) and different radio waves fallen. The technique which used in this study was the electrostatic probe down to see the I-V characteristic properties of this sensor to calculate the electrons energy distribution function inside the discharge system.
\end{abstract}

Keywords: Magnetic Field, Capacitive-Coupled RF Discharge, Electron Energy Distribution Function (EEDF), plasma glow discharge.

\section{المقدمة}

التفريغ الكهربائي في الغازات من المواضيع المهمة إذ يستخدم هذا التفريغ في مجالات مختلفة منها صناعة الاككترونيات

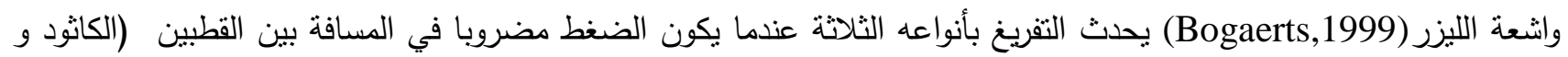
الأنود) حيث يكون حاصل ضرب الضغط الداخلي للمنظومة مضروباً في المسافة بين القطبين كبيراً والتيار الكلي منزايداً (Bijacac) (et al., 2002) حيث يمكن تصنيف التفريغ الكهربائي في الغازات عند الحالة المستقرة إلى ثلاثة أنواع وهي: 
1- تفريغ تاوسند (Townsend Discharge) في هذا النوع من التفريخ تتكون الايونات بزيادة الفولتية المسلطة على الأقطاب ويحدث عندما تكون الفولنية ثقريباً ثابتة خلال أنبوبة التقريغ الكهربائي غير معتمدة على زيادة التيار ومن النادر انبعاث أي ضوه من هذا التفريخ لذلك يدعى غالبا بالتقريغ المظلم (Howatson,1976) .

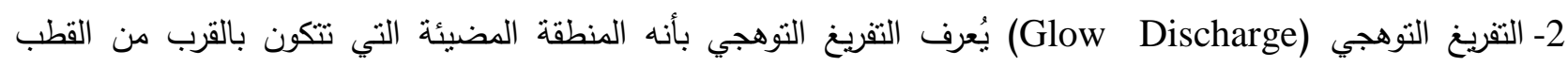
السالب وتكون مفصولة عنها بفضاء مظلم، وينبعث نتيجة لهذا التفريخ ضوءاً مرئيا ينوزع على طول منظومة التقريغ نتيجة لمرور تيار التفريغ في المنظومة المملؤة بغاز نادر عند الضغط الواطئ (Chapman, 1980). 3- تفريغ القوس (arc Discharge) عند المرحلة الاخيرة من التفريغ الكهربائي تتهار الفولتية بسرعة شديدة ويزداد التيار بصورة أكبر عندها ينتقل التفريغ من التوهجي الى القوس ولا يمكن وصف عملية الانتقال بالكامل عند زيادة التيار ولكن بمكن السيطرة

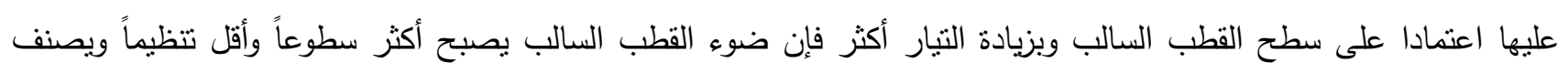
تفريغ القوس حسب عملية انبعاث الالكترونات من الكاثود، حسب الضغط أو حسب الألية الني ينزن بها القوس حرارياً ( الراشدي، . (2008

التفريغ الراديوي

يتميز التقريغ الراديوي بإمكانية انتاج البلازما حتى عند وضـع مـادة عازلة على الاقطاب إذ أن نطاق التردد الذي يمكن

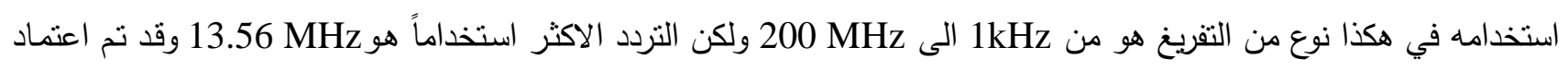

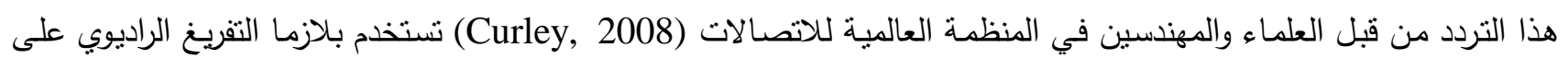

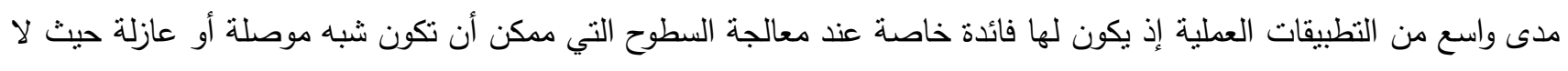

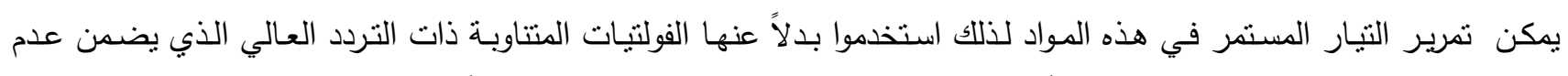

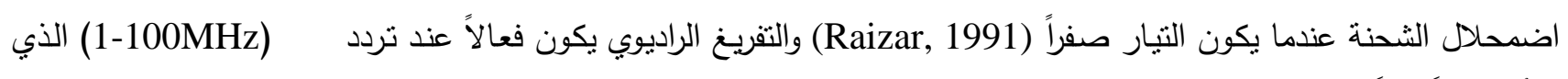
and Schmidt,

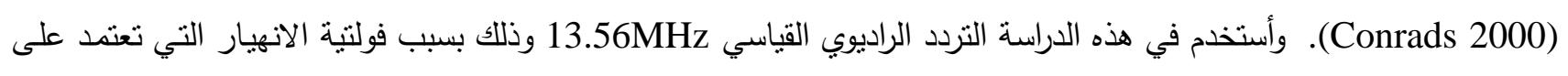

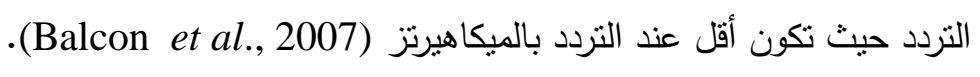

التفريغ الراديوي السعوي ينشأ التفريغ الراديوي السعوي بتسليط قدرة ذات تردد عالي على الاقطاب المتوازية التي يمكن أن تكون مكسوة بمادة عازلة يتم

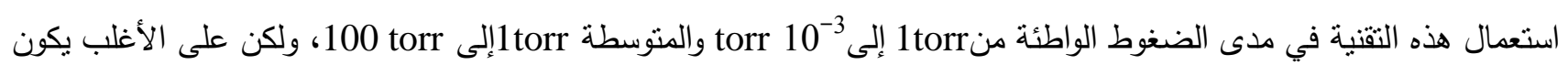
استخدام الضغوط الواطئة في المنظومات النطبيقية الصناعية للتفريغ CCP (Turner,1993). الفولتية والتيار للموجات الراديوية

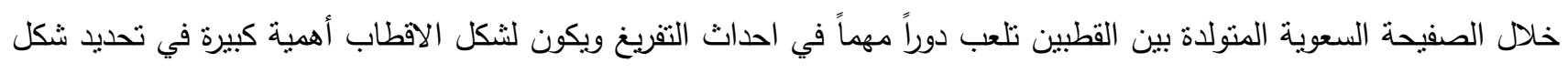
الانبوبة المستخدمة في دراسة التفريغ وينم ربط مصدر القدرة مع الخلية بواسطة دائرة مواءمة سعوية تدعى (Macting) Network) الضائعة (Norstrom,1979) تدخل البلازما المتولدة سعويا في معالجة أنواع متعددة ومختلفة من المواد الموصلة وغير الموصلة كالأدوات المايكروالكترونية والعينات البايولوجية (Lazovic et al., 2009) أن التردد 13.56 MHz الذي بستعمل في التفريغ الراديوي السعوي يدخل في بناء الدوائر المتكاملة وعمليات الترسيب بواسطة عملية الترذيذ على رقائق السليكون .(Chapman,1980) 
تأثير المجال المغناطيسي

يستخدم المجال المغناطيسي على مدى واسع من التطبيقات الصناعية ومن المعروف بأن أي شحنة متحركة تتتج مجالاً

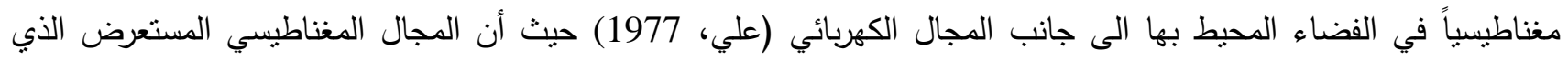
يكون موازياً للهدف (Target) يعمل على تقليل طاقة الاككترون عند الانتقال من الكاتود الى الانود والذي يؤدي الى تأين الغاز

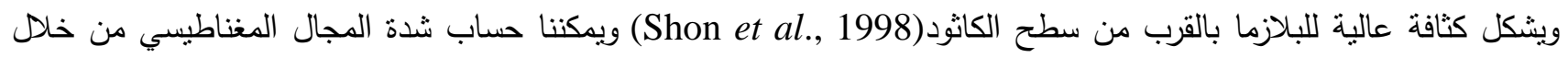
$B=\frac{\mu_{0} N I}{l}$ استخدام قانون أمبير (علي، 2010) الذي يُعطى بالعلاقة التالية:

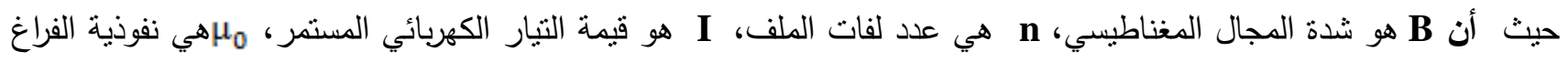
وقيمتها المجس الالكتروستاتيكي عند إدخال قطب إضافي إلى البلازما وربطه بمصدر فولنية منفصل عن القطب الموجب يتكون لدينا ما يسمى بالمجس

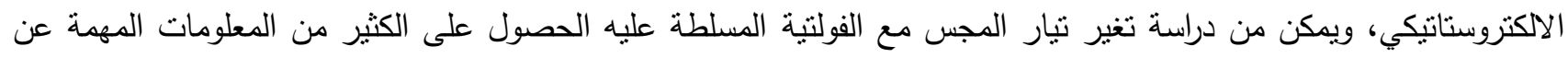

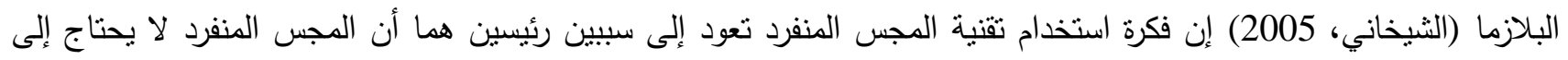

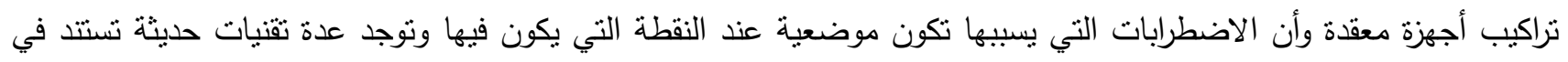

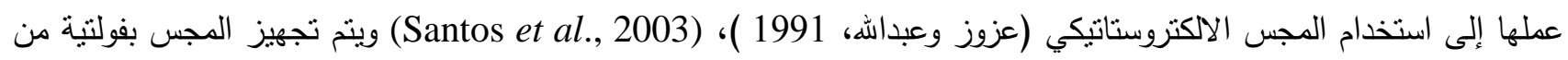
خلال مجهز قدره خارجي منفصل وتبعاً لذلك فإن نياراً يسري في المجس ينم قياسه. ومن دالة الخواص (I=f (V)) يتم رسم منحنى الخواص(I-V) ومن ثم يمكن حساب معظم المعلمات الفيزيائية للبلازما، وبصورة رئيسية قياسات دالة التوزيع الطاقي للالكترونات(Bricha et al., 2003) (EEDF) لا يعتمد مقدار التيار الكهبائي في المجس على متغيرات البلازما وإنما يعتمد على مساحة سطح المجس الذي يقوم بتجميع الثحنات (عبداله، 2006). دالة التوزيع الطاقي دالة التوزيع الطاقي للاكترونات تعتبر المفتاح الرئيسي لدراسة معلمات البلازما فضلا عن التحليل للتركيب الداخلي للغازات

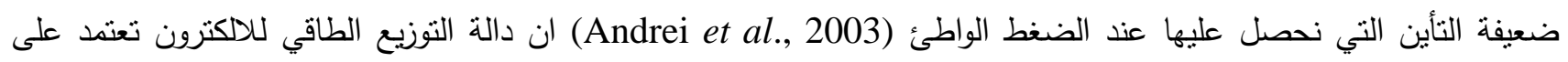
مجموعة من العوامل الخارجية منل: الأبعاد الهندية لمصدر البلازما، ضغط الغاز، معدل الجريان، الطاقة المصروفة وغيرها. ويمكننا حساب دالة التوزيع الطاقي (E) من المشتقة الثانية لمنحني خواص مجس لانكمور من خلال علاقة درايفستون

$$
f(E)=\frac{(8 m V)^{\frac{1}{2}}}{A e^{\frac{3}{2}} n e^{2}} \frac{d^{2} I}{d V^{2}}
$$

(Azooz , 2005)

حيث أن m هي كتلة الإكترون، e شحنة الإككترون، V الفولتية المسلطة على المجس، A هي مساحة مقطع المجس وn هي كثافة الاككترونات ولكون دالة التوزيع الطاقي هي عبارة عن وصف إحصائي للبلازما ضمن فضاء سرعي هني أو طاقي عند زمن معين (Holt and Haskel, 1965) فيمكنا على الأقل الحصول على الـ (EEDF) بصورة مباشرة ومن خله حل معادلة بولتزمان المتضمنة جميع عمليات التصادم المحتملة. 


\section{الجانب العملي}

تم أستخدام أنبوبة زجاجية يبلغ طولها (15.5cm) وقطرها الداخلي (4cm) موصولة بأنبوبة التقسيم عن طريق الفتحة

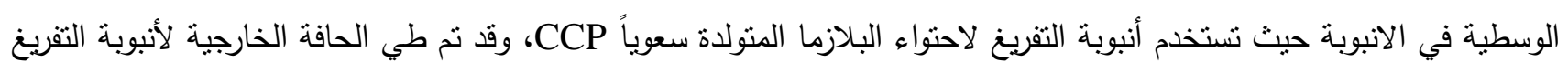

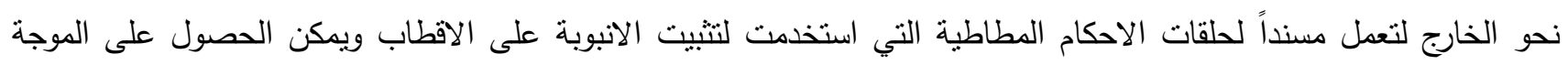
الراديوية اللازمة لإنتاج التفريغ السعوي من خلال استخدام مولد الموجة الراديوية ذات التردد 13.56 MHz وبقدرة متغيرة -0) 400Watt) حيث يربط هذا المولد بوحدة مواعمة (Matching unit) لكي لا يحدث انعكاس وضياع في الموجة الراديوية وقدرتها

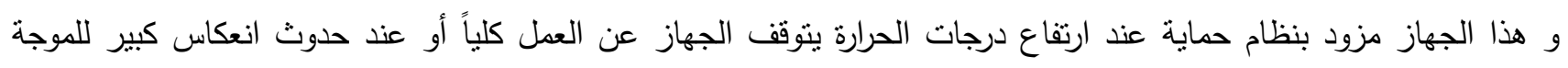
المسلطة على البلازما ومن أجل الحصول على قيم دقيقة للتيار والفولتية وخالية من التشويش كان لابد من استخدام دائرة الحجب لهب

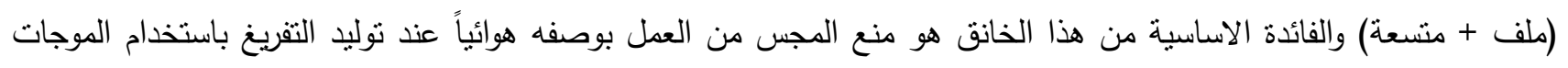

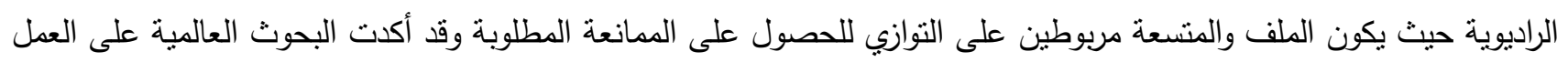

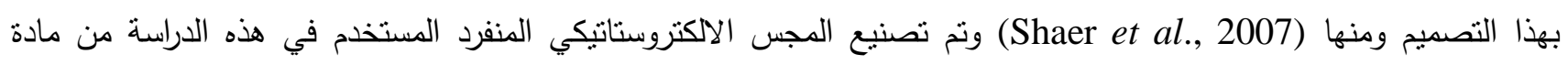

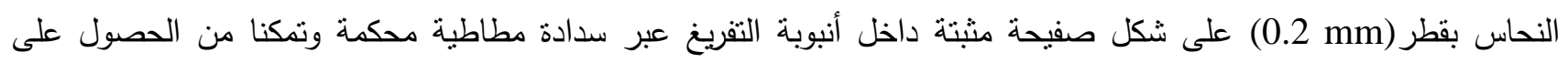
المجال المغناطيسي المستعرض من خلال تصنيع ملف يحيط بحجرة التقريغ الذي نم لفه يدوياً بقطر (0. الملف بحدود (1500) لفة بعد تحديد الموقع ولتجنب انفراط الملف من الجوانب والذي يقود حنماً الى تتوه في شكل المجال المغناطيسي فقد قمنا بتثبيت حلقات مطاطية على جانبي الملف وتم قياس شدة المجال المغناطيسي بأستخدام جهاز (Gaussmetar)

المستخدمة في هذه الدراسة موضحة بالثكل (2).

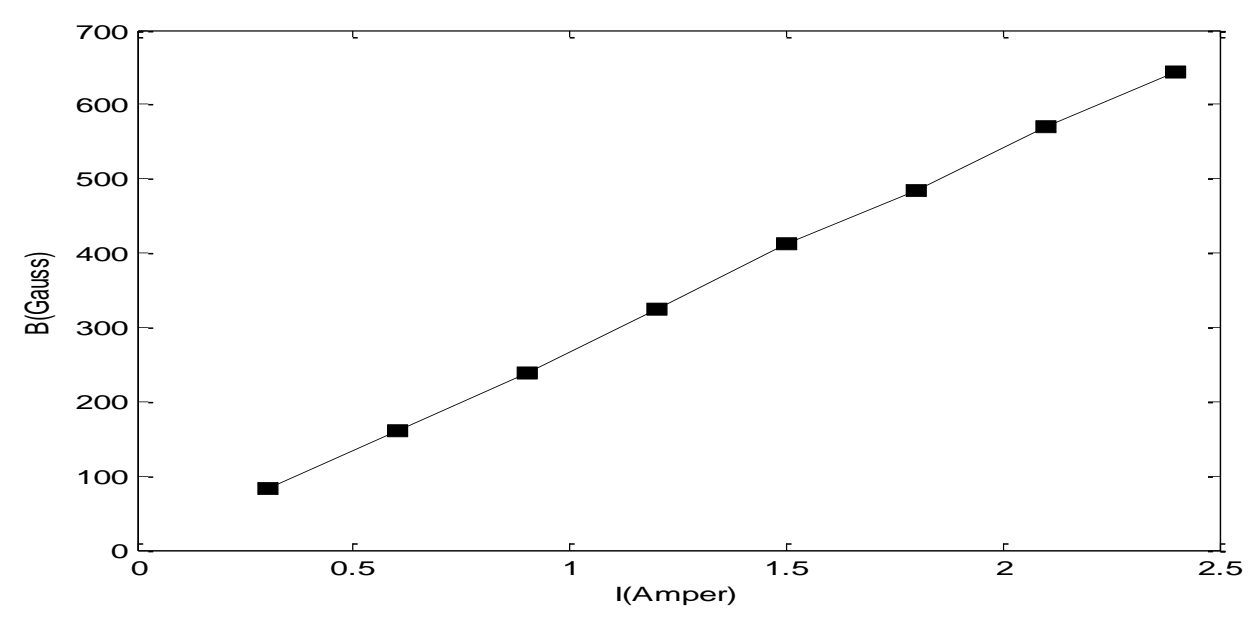

الثكل 1: معايرة المجال المغناطيسي 


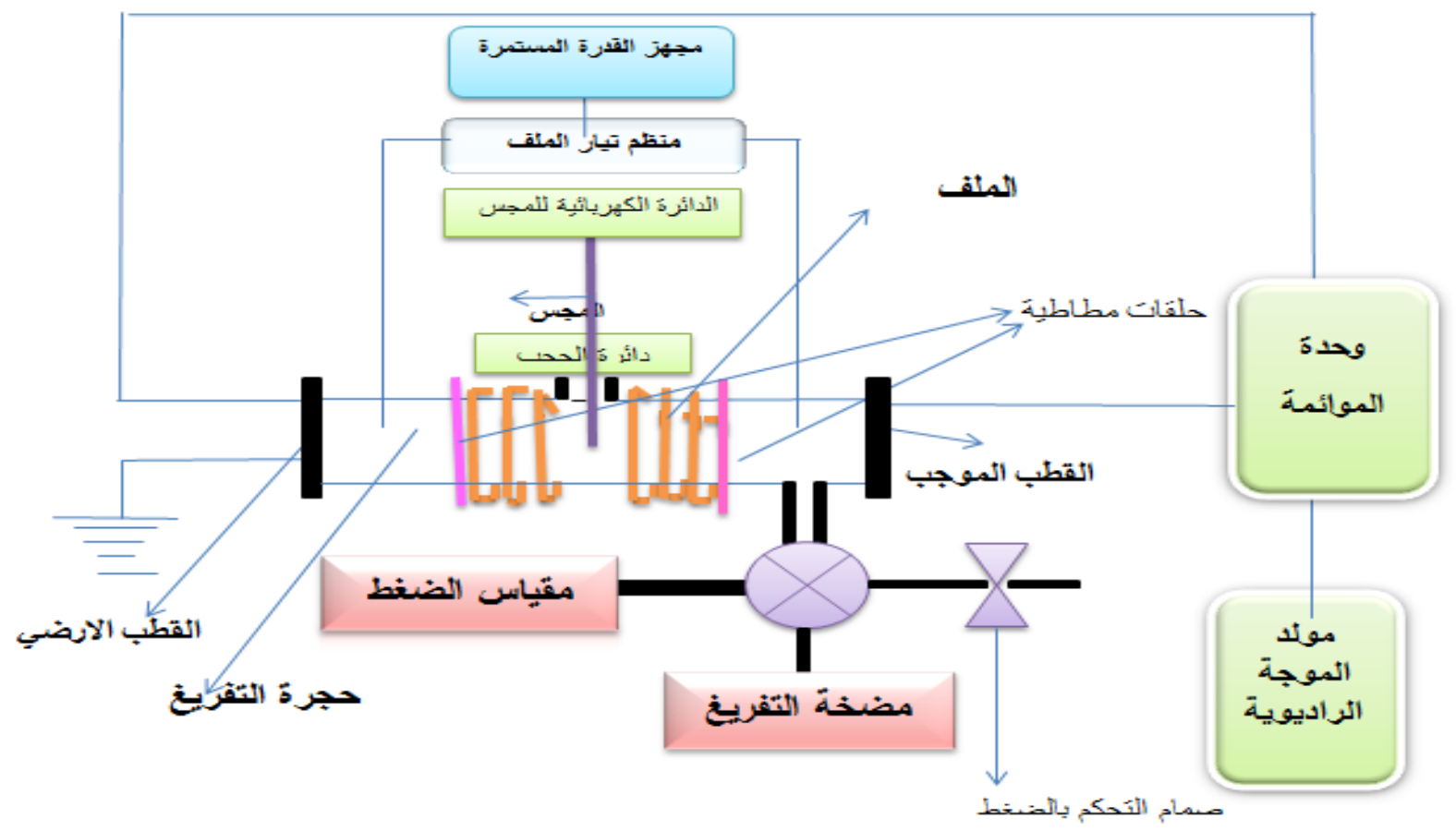

الشكل 2: المخطط التوضيحي للمنظومة

النتائج

لقد تم الحصول على عدد كبير من منحنيات خط الخواص في هذه الدراسة والتي سوف نتمكن من خلال تحليلها احتساب

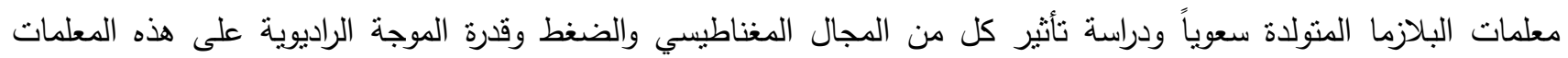
الاشكال (3) الى (6) توضح عملية موائمة البيانات التجريبية وضبطها للحصول على الخط المطلوب بشكل منتظم. ونلاحظ تطابق خط الخواص التجريبي مع خط الخواص القياسي وفي بعض الحالات لم نتمكن من الحصول على منطقة تيار التشبع الايوني من

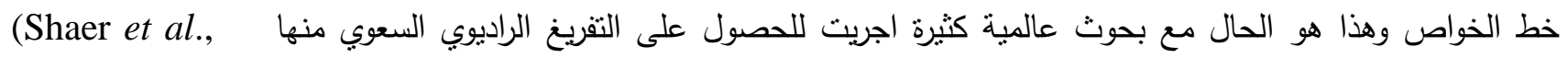
(2007) ( الساعور ، 2011)، (Al-Rawachy and Al-Saoor, 2013) 


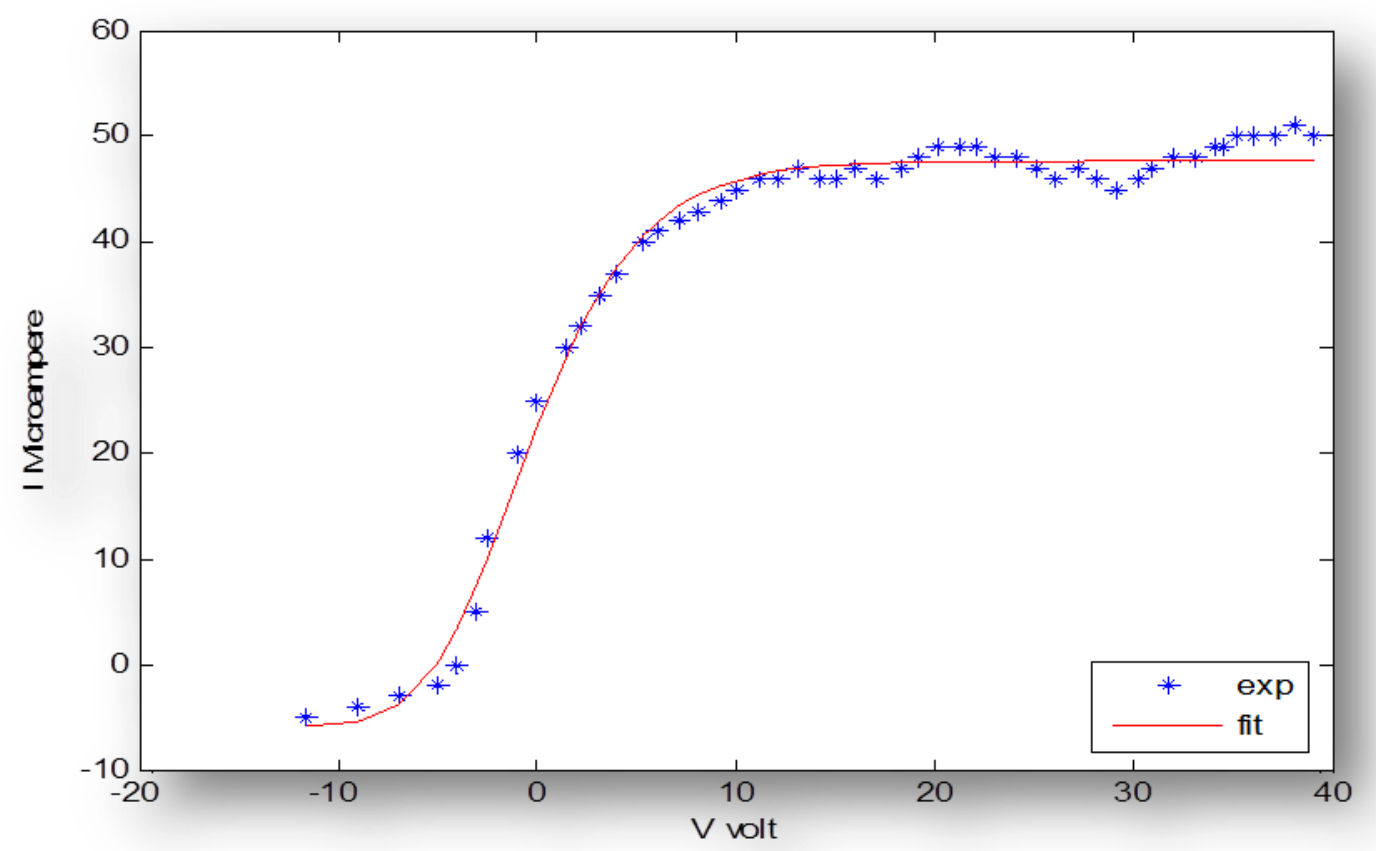

الثكل3 : منحني الخواص التجريبي للمجس الاكتروستاتيكي عند الضغط (1.5 Pascal) وقدرة (50 Watt) ومجال (0 Gauss)

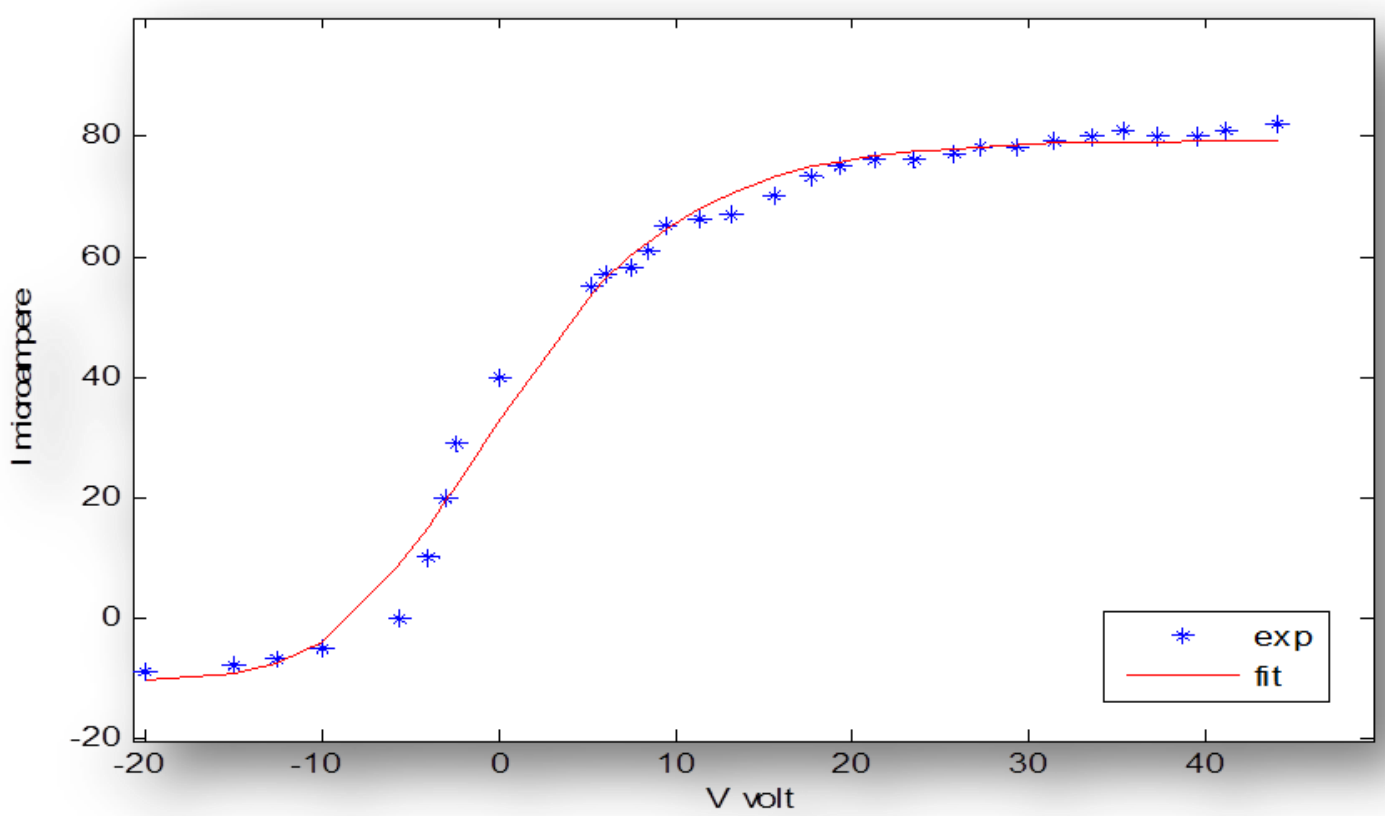

الثكل 4: منحني الخواص التجريبي للججس الاكتروستاتيكي عند الضغط (5x10-2 Pascal) وقرة (50Watt) ومجال مغناطيسي (239 Gauss) 


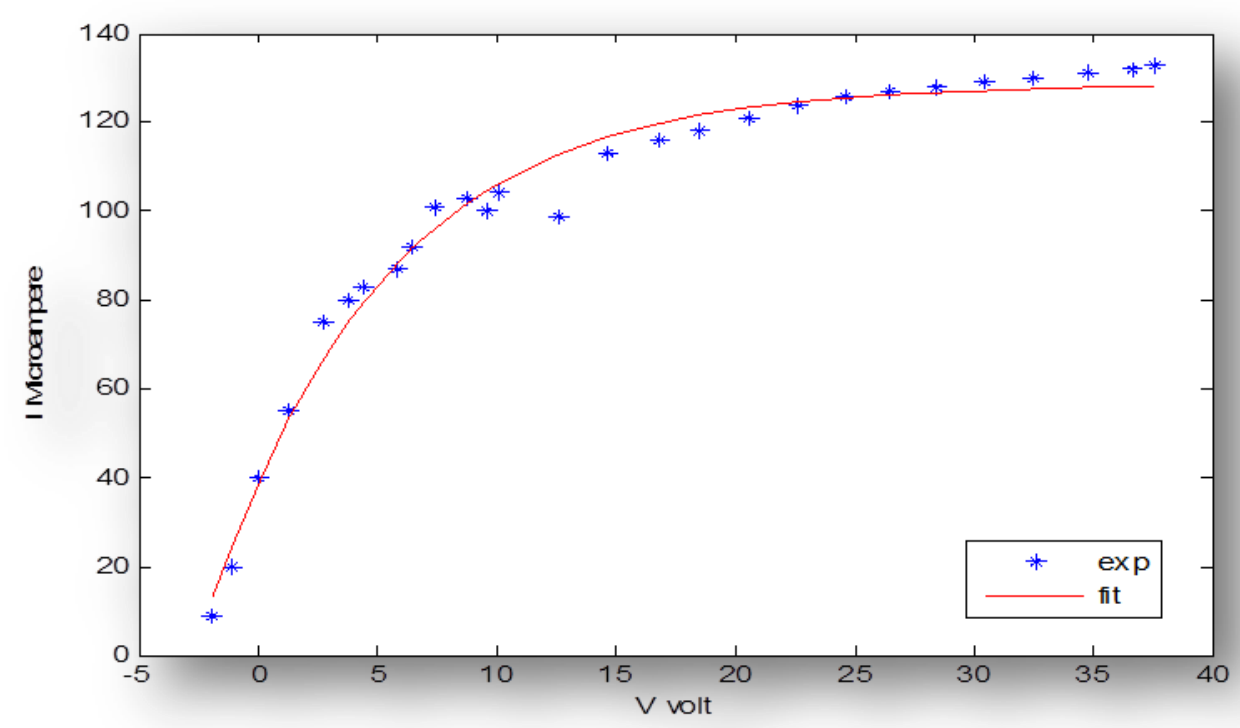

الثكل 5: منحني الخواص التجريبي للمجس الاكتروستاتيكي عند الضغط (5.6x10 Pascal ) وقرة (90 Watt) ومجال (239 Gauss)

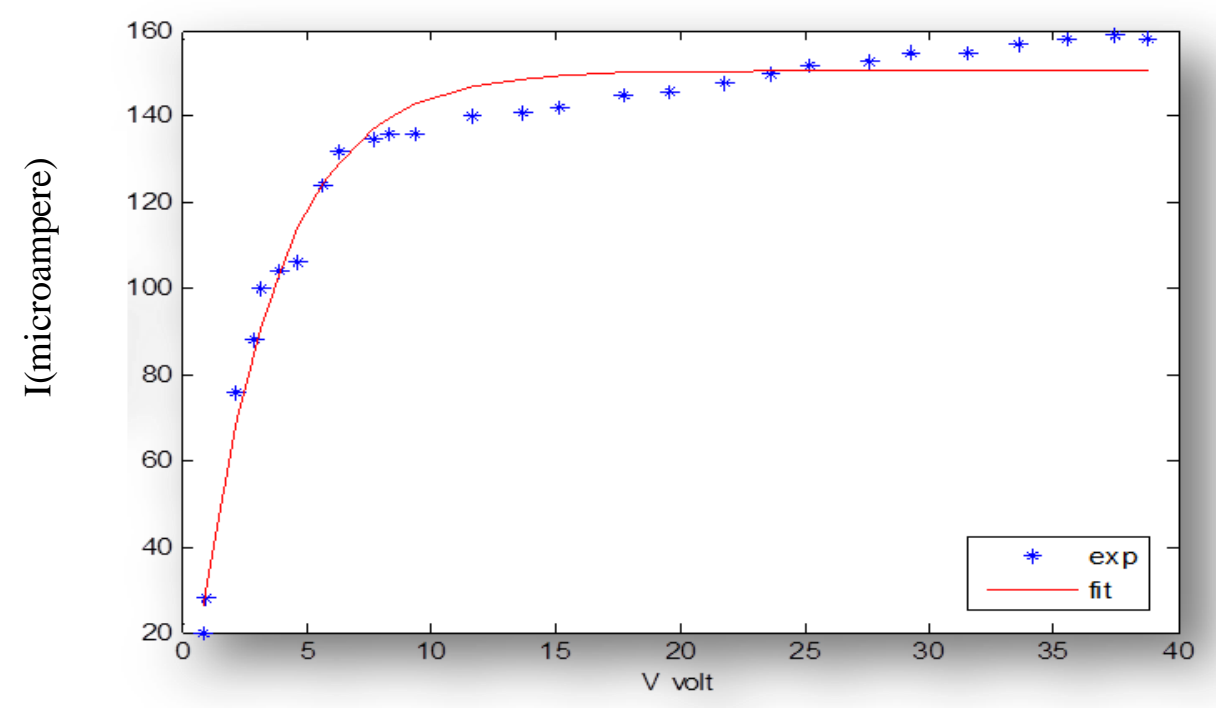

الثكل 6: منحني الخواص التجريبي للمجس الاكتروستاتيكي عند الضغط (1Pascal) وقدرة (70Watt) ومجال مغناطيسي (413 Gauss)

اما جهد البلازما فيعتبر من المعلمات المهمة في التفريخ الراديوي السعوي حيث يمكن ايجاده من خلال المشتقة الثانية للتيار

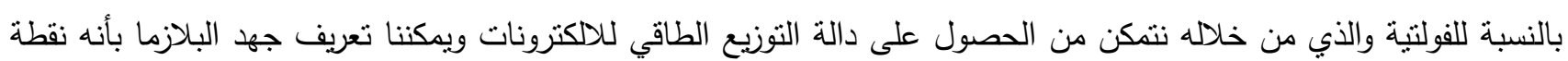

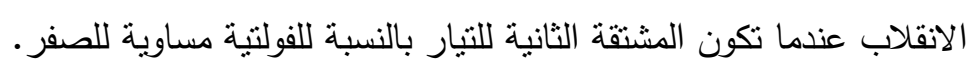




$$
\text { هيثم عبدالحميد الراوجي و إيمان يونس عبد }
$$

$$
\frac{d^{2} I}{d v^{2}}=0
$$

حيث استخدمت هذه الطريقة للحصول على جهد البلازما. والصيغة النهائية للمشتقة الثانية للتيار بالنسبة للفولتية موضحة بالمعادلة

$$
\begin{aligned}
d^{2} I / d V^{2}=a_{1}\left[\operatorname { t a n h } ^ { 2 } ( ( V + a _ { 2 } ) / a _ { 3 } ] \left[2 \tanh \left(\left(V+a_{2}\right) / a_{3}\right)-a_{1}\right.\right. \\
\left.+\left(a_{1} / a_{2}\right) \tanh ^{2}\left(\left(V+a_{2}\right) / a_{3}\right)\right] \exp \left[a_{1} \tanh \left(\left(V+a_{2}\right) / a_{3}\right)\right]
\end{aligned}
$$

(Azooz, 2008) (4)

الأشكال (7)، (8) تمثل جهد البلازما لبعض الحالات كنموذج من البيانات التي تمكنا من الحصول عليها في هذه الدراسة بوجود المجال المغناطيسي وعدم وجوده.

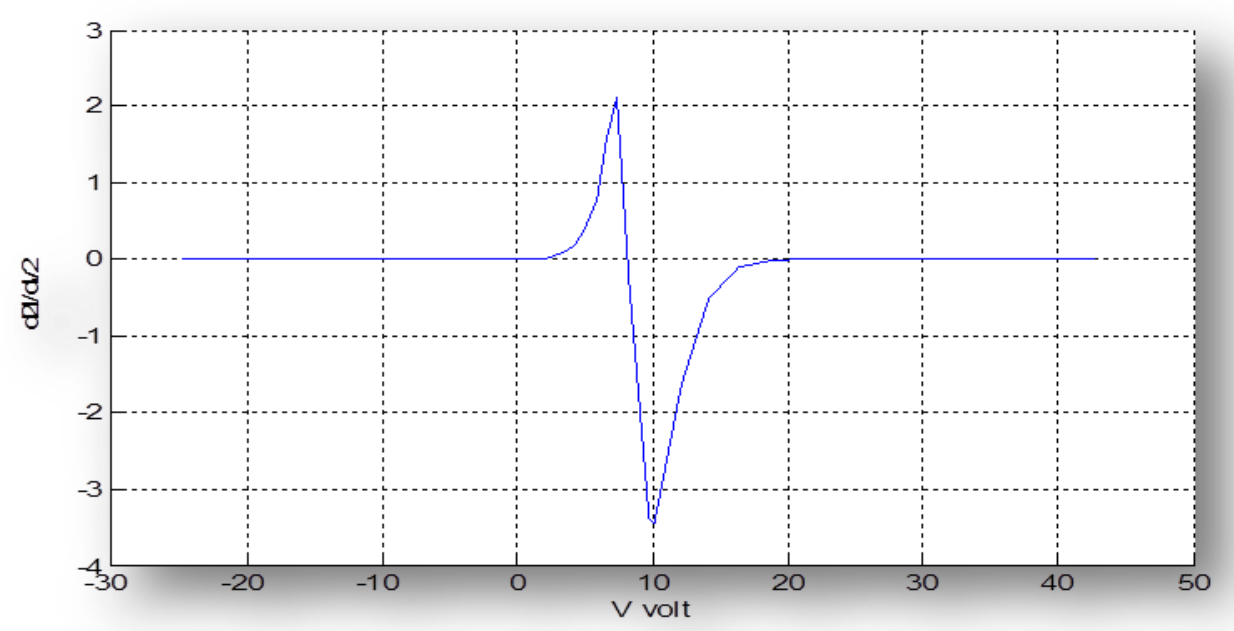

الثكل 7: فولتية المجس مع المشتقة الثانية للنيار بالنسبة للفولتية عند ضغط (5x10-2 Pass) وقدرة (110 Watt) .(82 Gauss) مغناطيسي

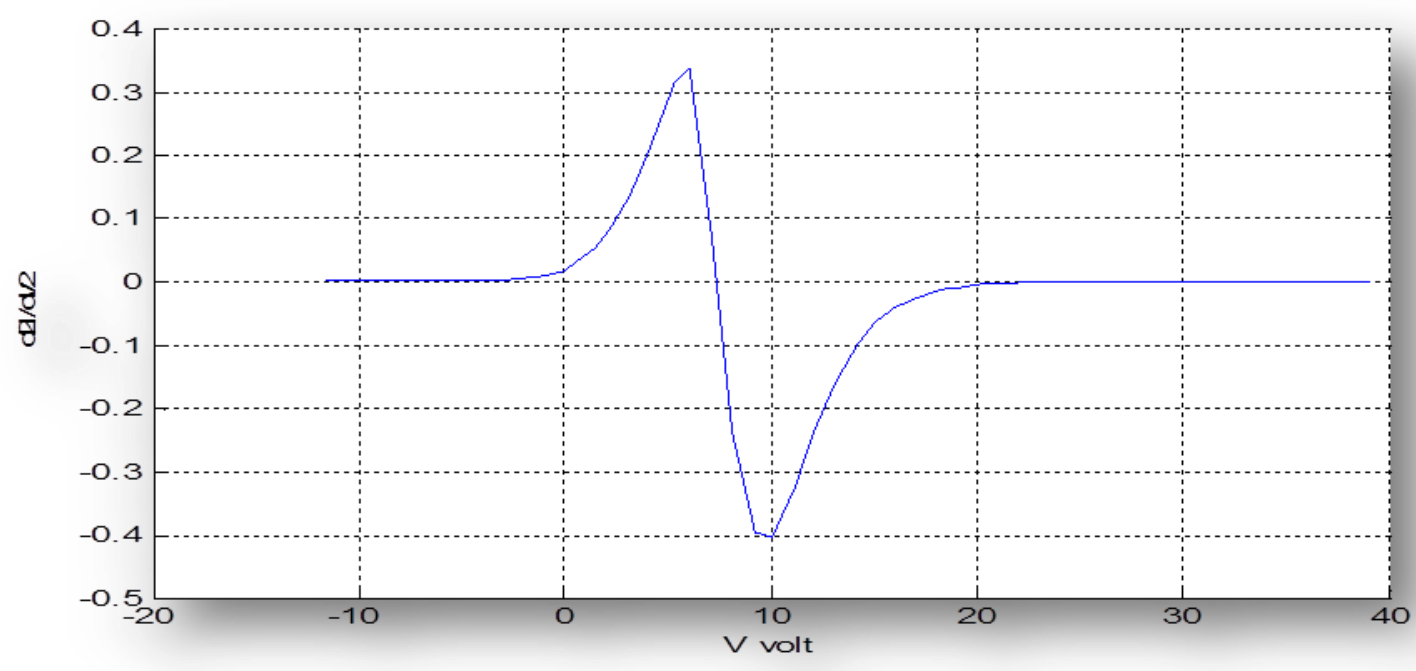

الثكل 8: فولتية المجس مـع المشتقة الثانية للتيار بالنسبة للفولتية عند ضغط (1.5 Pass) وقدرة راديوية (50) Watt) ومجال مغناطيسي(0 Gauss) 
ان تأثيرات التأينات الثانوية سوف تظهر وبشكل واضح نتيجة لامتلاك الاككترونات حركية عالية مما يؤدي الى تصادمها مع

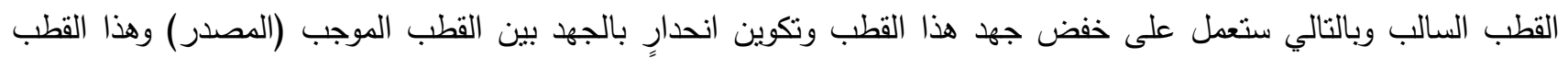

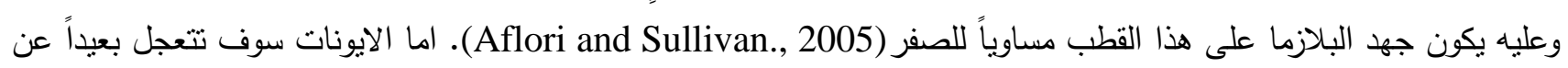
القطب السالب ولكن المسافة التي يمكن أن ثقطعها سوف تكون صغيرة ويمكن اهمالها قبل أن يعكس المجال اتجاهه مرة أخرى

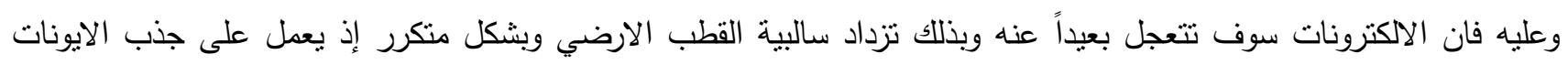

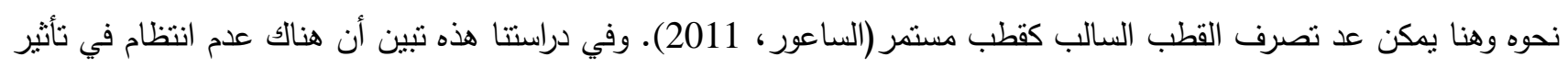
قدرة الموجة الراديوية والضغط على جهد البلازما كنتيجة لتأثنر المجال المغناطيسي المستعرض لعدم وجود تأثنير واضح ومنتظم للمجال المغناطيسي على هذا الجهد الذي يعمل على تحديد الحركية الاكترونية كنتيجة للحجز المغناطيسي على الالكترونات وكما

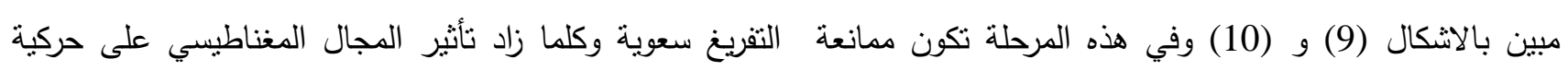

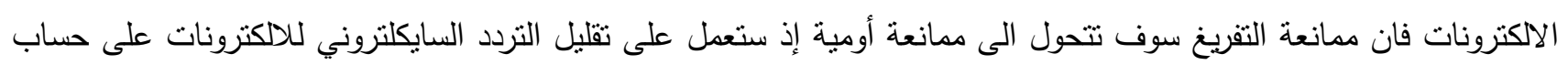

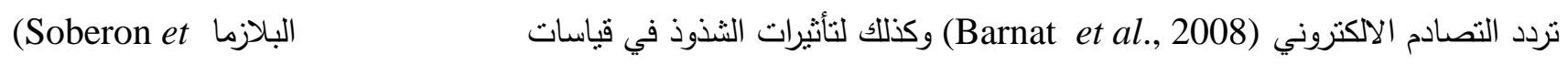
.al., 2003)

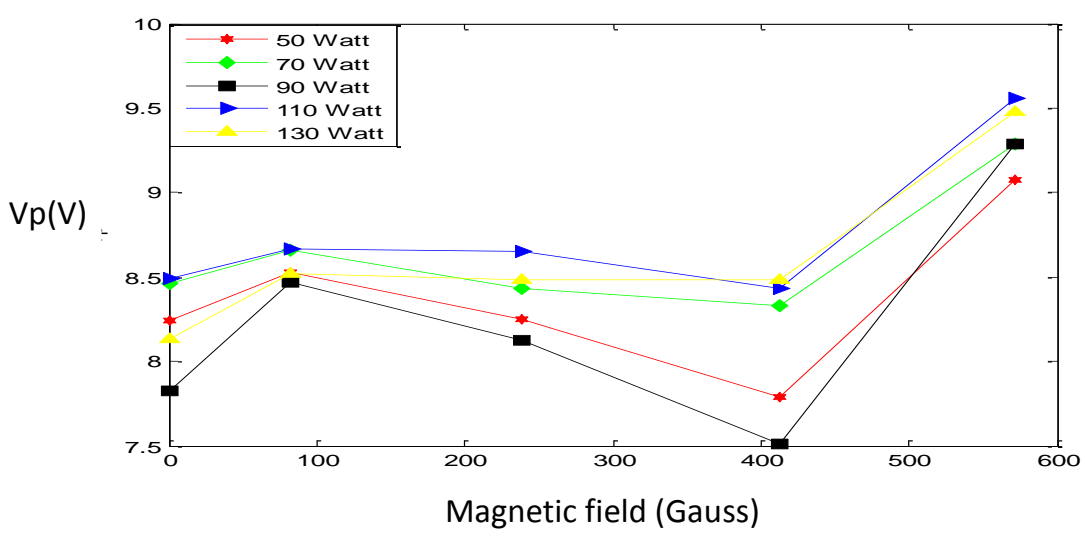

الثكل 9: علاقة جها البلازما مع القدرة للمجالات المغناطيسية المستعملة بثبوت الضغط عند ( 1Pascal)

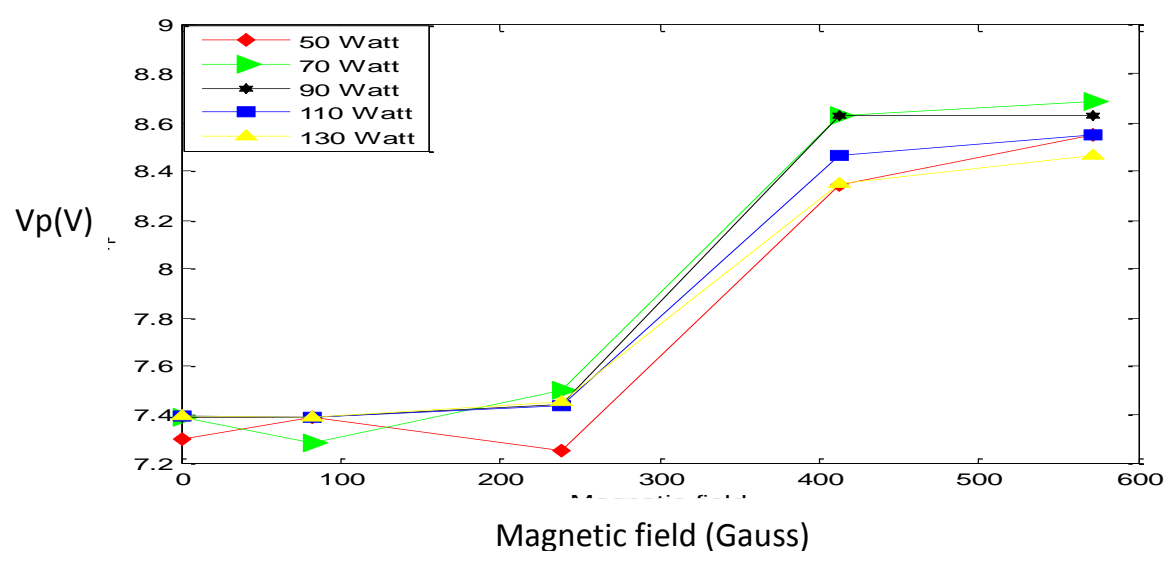

الثكل 10: علاقة جهر البلازما مع القدرة للمجالات المغناطيسية المستعملة بثبوت الضغط عند (1.5 Pascal) 
يمكن حساب دالة التوزيع الطاقي باستخدام طريقة المشتقة الثانية لمنحني الخواص في المنطقة الانتقالية من منحني الخواص للمجس الالكتروستانيكي والاشكال (11)و (12) تمثل دالة التوزيع الطاقي التي تمكنا من الحصول عليها.

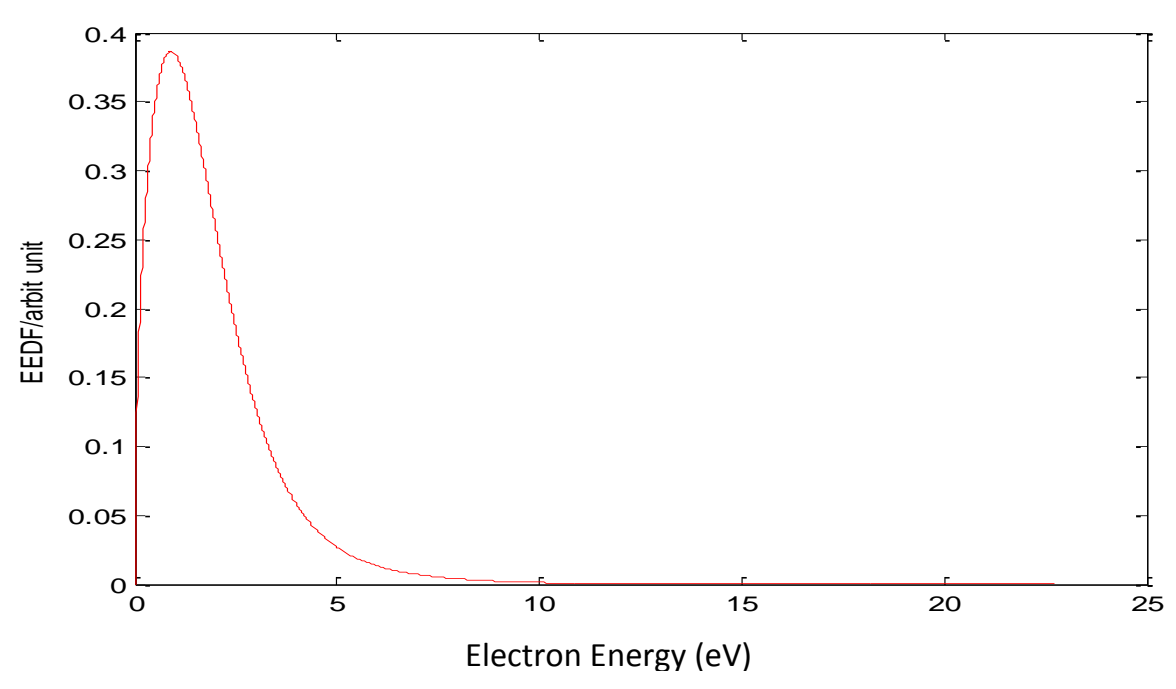

الثكل 11 : دالة التوزيع الطاقي عند الضغط (239 Gaust) (1.5 Pascal) ومجال مغناطيسي (20)

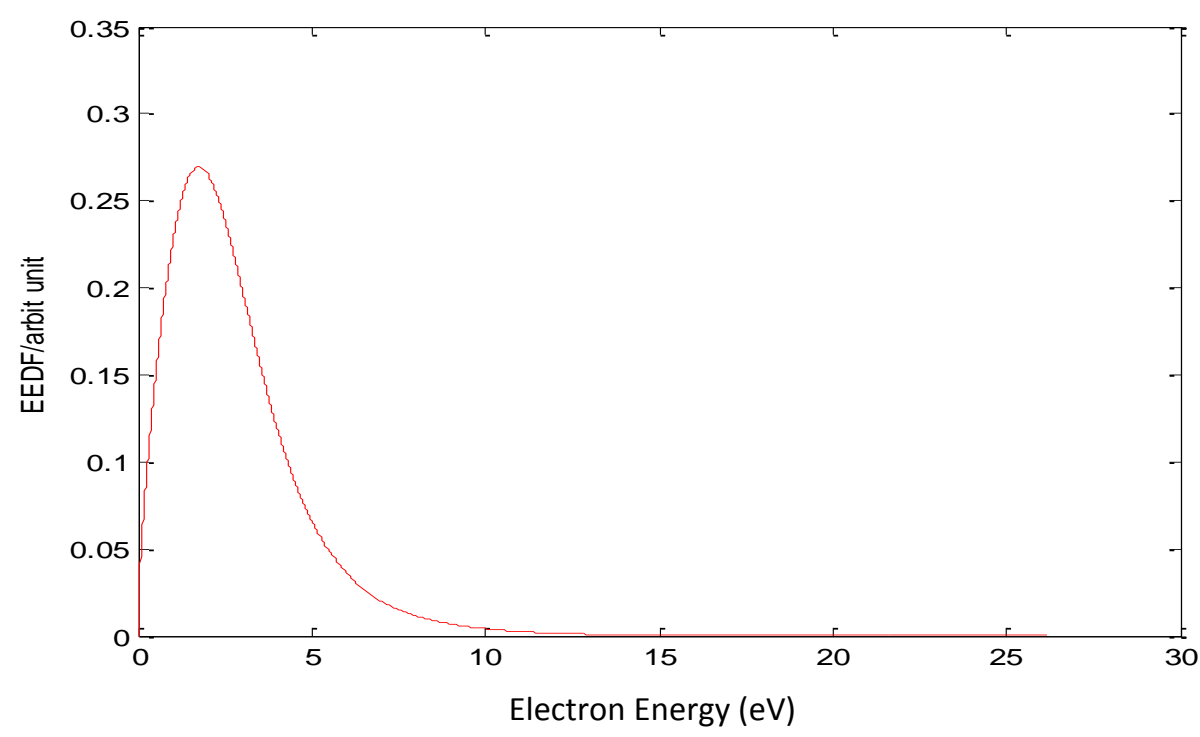

الثكل 12: دالة التوزيع الطاقي عند الضغط (5.6X10-1 Pascal) وقرة (70 Watt) ومجال مغناطيسي(413)

الثكل (13) يوضح دالة التوزيع الطاقي عند الضغط (5.6x10-1 Pascal) وقدرة (90 Watt) ولجميع المجالات المغناطيسية المستخدمة. إذ نلاحظ نطابقاً تاماً لدوال التوزيع الطاقي عند مختلف المجالات المغناطيسية وتكون في اعلى قمة عند المجال المغناطيسي (82 Gauss) وتتخفض بشكل تدريجي عند زيادة المجال المغناطيسي. وهذا يمكن أن يعزى الى عدم التوازن

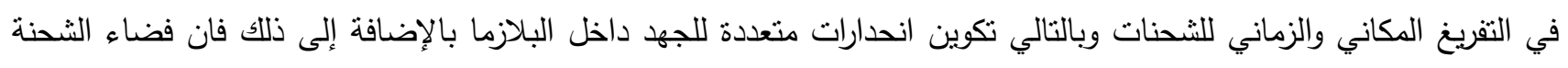
القريب من المجس سوف يتأثر بشكل كبير ومباشر بالظروف النتغيلية المختلفة لمنظومة البلازما الراديوية المتولدة 
سعوياً (Godyak, 2006). إذ سيكون هناك خسارة كبيرة في طاقات الاككترونات السريعة عند الجدران كنتيجة لأغفال الحجز

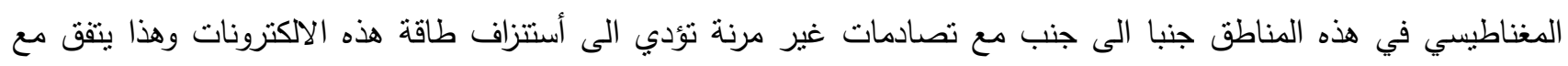

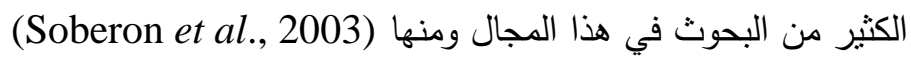

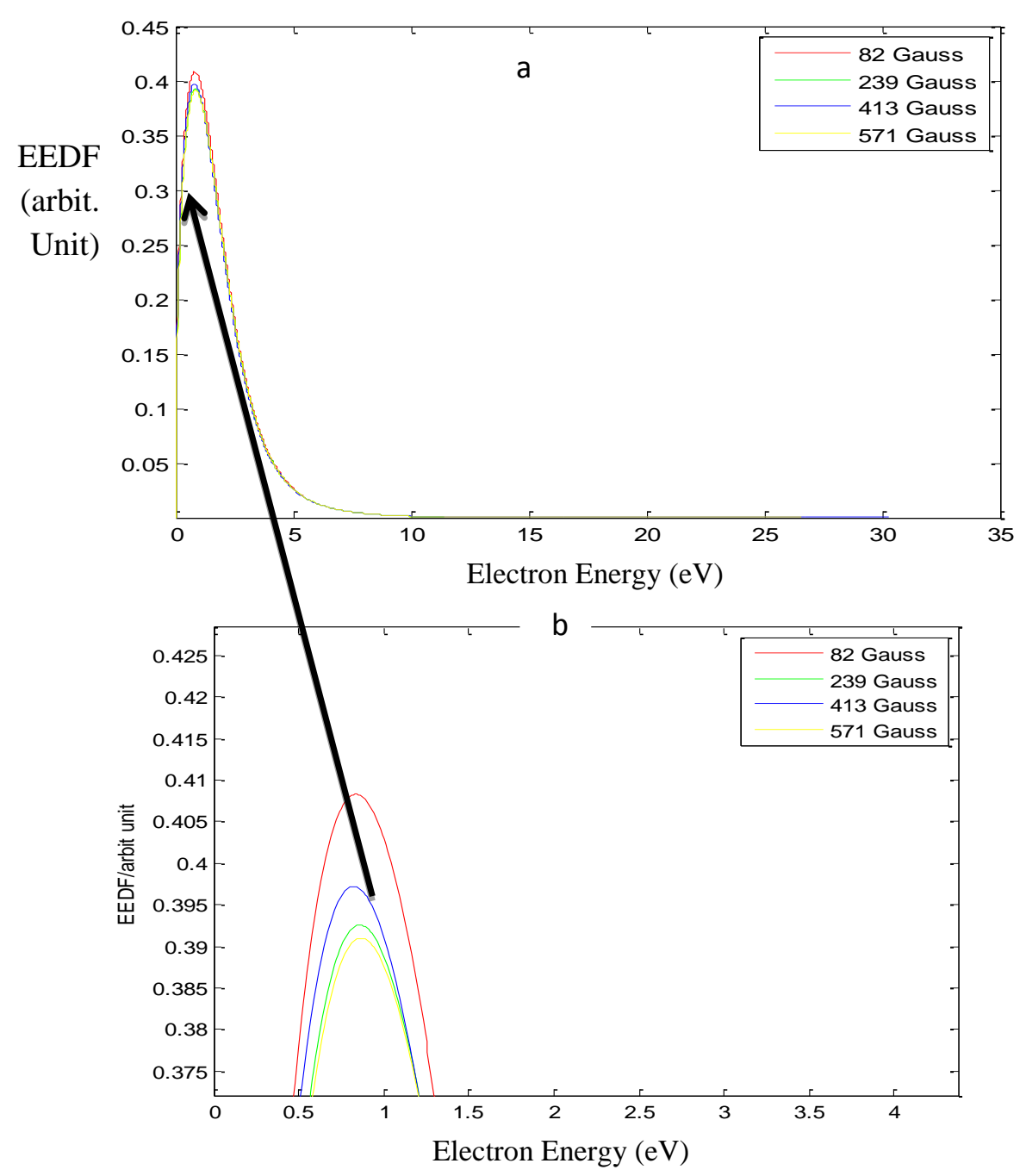

الشكل 13: دالة التوزيع الطاقي عند الضغط (5.6x10 (1) وقدرة (90 Wascal)

أما الأثكال (14) و (15) تمثل مقارنة دالة التوزيع الطاقي التي حصلنا عليها مع الدوال التجريبية الثلاثة (فيرمي ديراك،

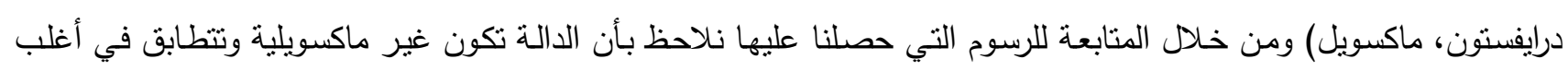

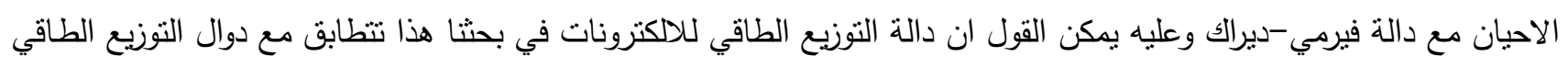
لبحوث اخرى إذ أظهرث هذه البحوث عدم انسياق الدوال التجريبية المحتسبة مع دالة ماكسويل نتيجة لغياب التوازن الثرموديناميكي في العمليات المباشرة والمعكوسة. كمثال على ذلك توليد زوج الكترون - ايون وتهيج الغاز نتيجة لتصادم الالكترونات السريعة داخل

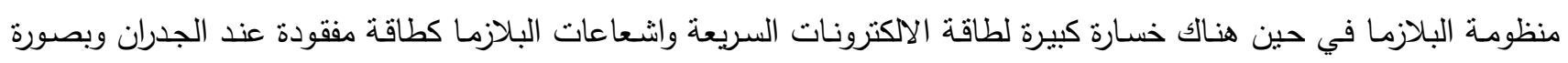


عامة يمكن القول بأن تصادم الكترون-الكترون نتيجة للقوى الكهربائية بينها يوفر دعماً لأن تكون دالة التوزيع الطاقي ماكسويلية

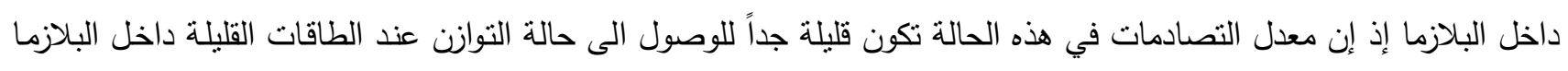

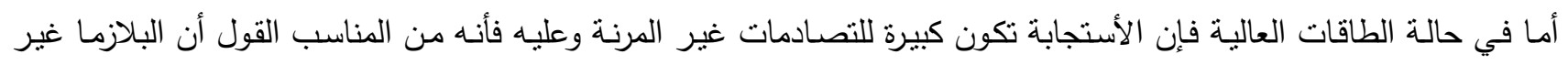

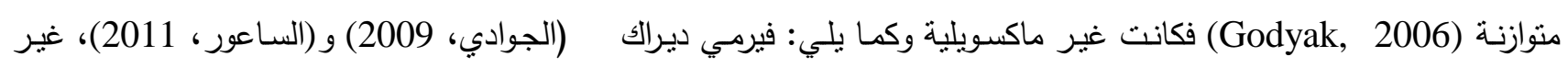
ماكسويلية (Chen et al., 2009) و (Homfray and Crowley, 2007) وكذلك وجود انتقال في دالة التوزيع الطاقي من دالة Maxwell

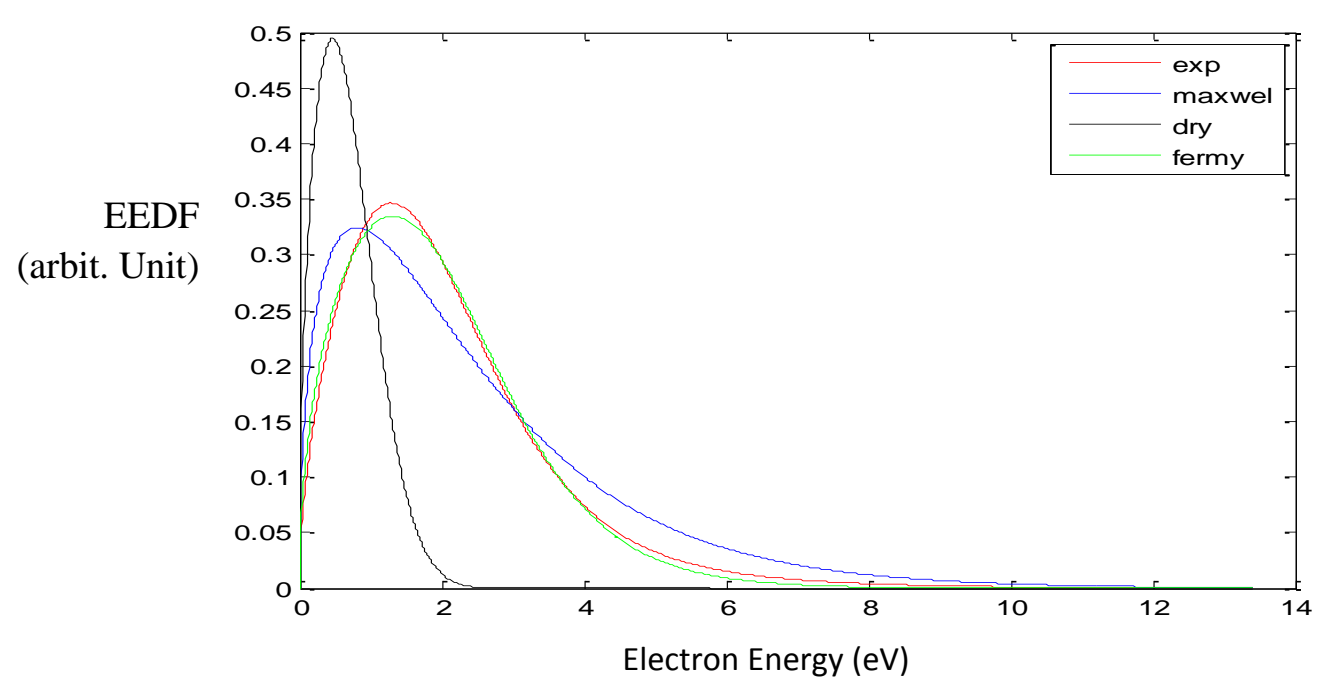

الشكل 14: دالة التوزيع الطاقي مقارنة بالدوال النظامية (ماكسويل، فيرمي ودرايفستون) عند الضغط (1.5 Pascal) وقدرة (82 Gauss) ومجال مغناطيسي (50 Watt)

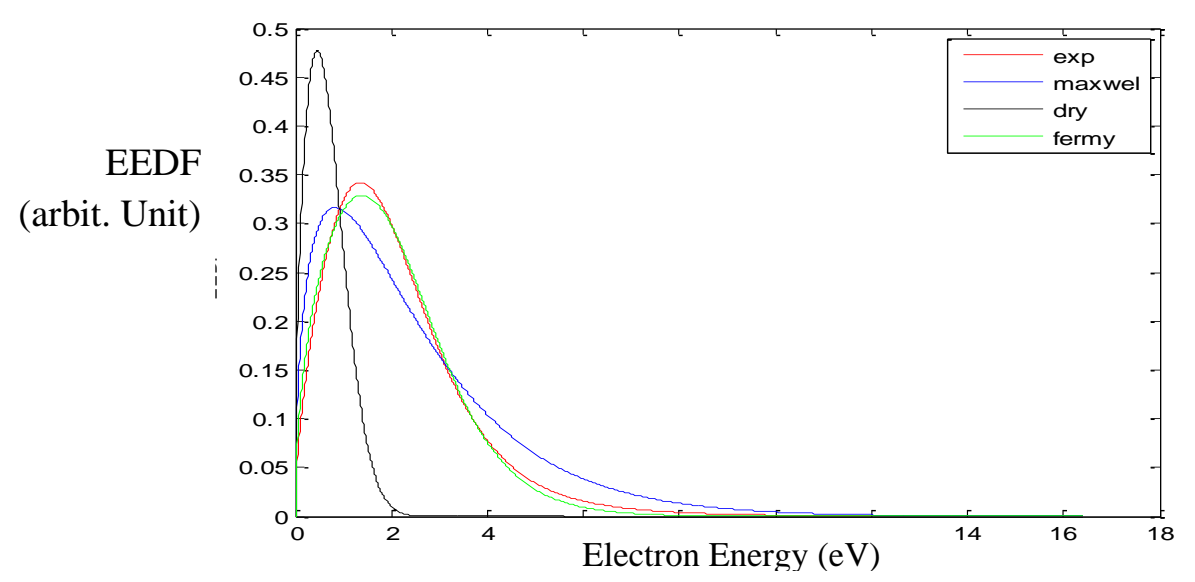

الثكل 15: دالنة التوزيع الطاقي مقارنة بالدوال النظامية (ماكسويل، فيرمي ودرايفستون) عند الضغط (130 Pascal) وقدرة

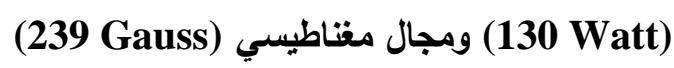
الاستنتاجات

خلاصة لما نقدم وبعد سلسلة من القياسات اجريت على البلازما المغناطيسية المنولدة سعويا في الهواء الجاف عند ضغوط مختلفة وقدرات مختلفة للموجة الراديوية الساقطة لمعرفة كيفية تصرف البلازما السعوية تحت تأثثر مختلف المجالات المغناطيسية 
ومن خلال تحليل خط الخواص للمجس الالكتروستاتيكي المستخدم في هذه الدراسة وجد نطابق تام على الاغلب مع خط الخواص

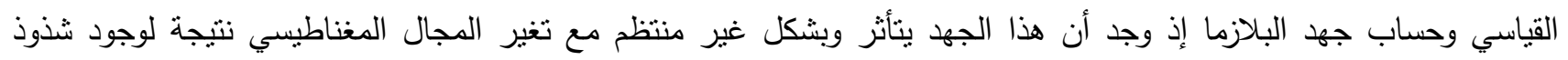

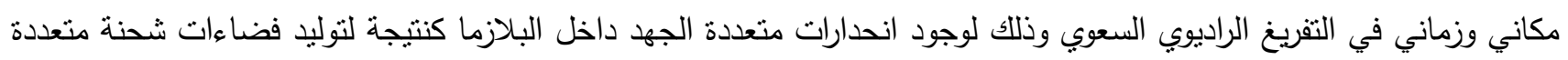
داخلها بالإضافة إلى تأثيرات مباشرة أخرى لهذا المجال على تصرف البلازما كقدرة الموجة الراديوية الساقطة وتغير الضغط داخل داخل

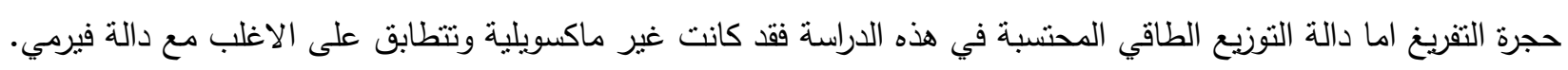
المصادر العربية

الجوادي، ياسر عبد الجواد (2009). "معلمات البلازما في التقريخ بالتردد الراديوي 13.56MHz". أطروحة دكتورا، كلية العلوم، قسم الفيزياء، جامعة الموصل، العراق.

الراثندي، ورقاء عمر عبد فارس (2008). "دراسة معلمات التقريغ التوهجي المستمر للهواء الجاف خلف القطب السالب بأستخدام

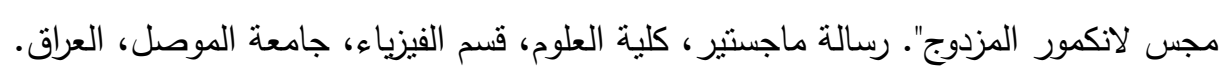

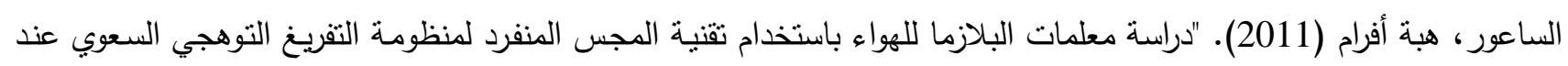
التزدد (13.56MHz)". رسالة ماجستبر ، كلية العلوم، قسم الفيزياء، جامعة الموصل، العراق.

الثيخاني، دلشاد صالح اسماعيل (2005). "تصميم واستخدام قطب جديد لدراسة التوزيع القطري لمعلمات بلازما التفريغ التوهجي". رسالة ماجستير، قسم الفيزياء، كلية العلوم، جامعة الموصل، العراق.

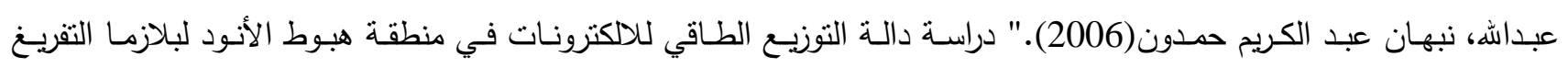

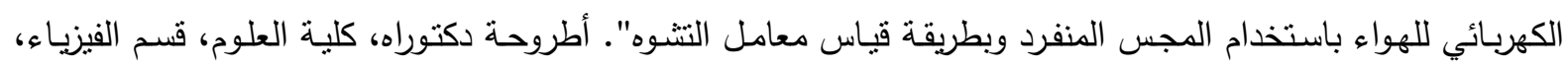
جامعة الموصل، العراق.

عزوز، عاصم عبد الكريم وعبداله رحمن رستم (1991). "فيزياء البلازما". مديرية دار الكتب للطباعة والنشر ، جامعة الموصل، العراق.

علي، زيـاد طـارق (2010). " تأثثر المجـال المغناطيسي على معلمـات التفريخ التوهجي الحثي باستخدام الموجـات الراديويـة 13.56MHz" علي، يحيى عبد الحميد (1977). الكهربائية والمغناطيسية، دار الكتب للطباعة والنشر، جامعة الموصل، العراق.

\section{المصادر الأجنبية}

Aflori, M.; Sullivan, J. (2005). Langmuir probe measurements in an A transverse asymmetrical RF discharge. Romanian Reports in Physics, 57 (1), 71-77.

Al-Rawachy, H.; Al-Sahoor, H. (2013). Investigation of the electron energy distrebution function in capacitively coupled (13.56 MHz) Radio Frequency Discharge in dry Air. Rafiden J. Sci., 24 (6), 82-95.

Andrei, H.; Covlea,V.; Baran, E. (2003). The smoothing and the digital processing of Langmuir probe characteristic. Romanian report in physics., 55 (2), (51-56).

Azooz, A.A. (2008). Four free parameter empirical parameterization of glow discharge for probe data. Review Sci. Instruments, 79,103501.

Azooz. A. A. (2005). Parameterization of electron energy distribution function in glow discharge plasma under RF electromagnetic fields. ISSN 1330-0008 Codenfizae 4, 13 (4), (151-160).

Balcon, N.; Aanesland, A.; Boswell, R. (2007). Pulsed RF discharge glow and filamentary mode at atmospheric pressure in argon. Plasma Sources Sci. Technol. 16, (217-225). 


$$
\text { هيثم عبدالحميد الراوجي و إيمان يونس عبد }
$$

Barnat, E.; Miller. P.; Paterson. A. (2008). RF discharge under the influence of a transverse magnetic field. Plasma Sources Sci. Technol, (17), 11.

Bogaerts, A.,(1999). The glow discharge: an exciting plasma. J. Analytical Atomic Spectr., (14). 1375-1384.

Bricha E.C.I.; Graham W.G.; Morrow T.; Steen P.G.; Thompson C.E. (2003). Analysis Procedure for Calculation of Electron Energy Distribution Functions from Incoherent Thompson Scattering Spectra. J. Appl. Phys., 94(1),110-114.

Champman, B. (1980). "Glow Discharge Processes". Wiley, Sons.

Chen, Z.; Donnelly, V.M.; Economou, D.J. (2009). Measurement of electron temperatures and electron energy distribution functions in dual frequency capacitively coupled $\mathrm{CF}_{4} / \mathrm{O}_{2}$ Plasmas using trace rare gases optical emission spectroscopy. J. Vac. Sci. Technol. A27 (5), (1159-1165).

Conrads, H.; Schmidt, M. (2000). Plasma Generation and Sources. Plasma Sources Sci. Technol, 9, (4), 441-454.

Curley, G.A. (2008). The dynamics of the charged particles in a dual frequency capacitively coupled dielectric etch reactor. Ph.D. Thesis, Polytechnique college, Germany.

Godyak, V.A. (2006). Nonequilibrium EEDF in Gas Discharge Langmuir probe data. Review Sci. Instruments. 79, 103501.

Holt, E.H.; Haskell, R.E. (1965). "Foundation of Plasma Dynamics". MacMillan, New York, USA.

Homfray, D.; Crowley, B. (2007). A noval System for the direct measurement of the electron energy distribution function by Langmuir probe in ion sources. ELSEVIER, 82, 829-835.

Hopkins, M.B. (1995). Langmuir probe measurements in the gaseous electronics conference RF reference cell. J. Res. Natl. Inst. Stand. Technol., 100(4), 415-425.

Howston, A.M. (1976). "An Introduction of Glow Discharge". Pergaman Press Oxford, $2^{\text {nd }}$ ed.

Lazovic, S.; Puac, N.; Petrovic, Z.Lj. (2009). Langmuir probe measurements of large scale RF asymmetric capacitive coupled plasma. Cancun, Mexico, $29^{\text {th }}$ ICPIG, July. pp.12-17.

Norstrom, H. (1979). Experimental and design information for the calculation impedance matching networks for use in sputtering and plasma chemistry. Vacuum, 29(10), 314-3.

Raizar, L. (1991)." Gas Discharge Physics". Speinger (Germany), ISEN 0-387-1942-2.

Santos M.F.S.; Massi M.; Petraconi G. (2003). Automaco De Um Sistema De Sonda De Langmuir Para Caracterizaco De Plasmas. Dept.de Fisica, Inst. Tec. de Aeronutica, Brasil, E-mail: Milton@h8.ita.br ؛ massi@ita.br؛ gilberto@ita.br

Shaer, M.; Soliman, A.; Massoud, A.; Mobasher, M.; Wuttmann, M. (2007). Comouterized Langmuir probe measurements in a capacitively coupled RF discharge. $28^{\text {th }}$ ICPIG, July. pp.15-20, Prague, Czech Republic.

Shon, C.H.; Lee, J.K.; Lee, H.J.; Yang, Y.; Chung, T.H. (1998). Velocity distributions in magnetron sputter. IEEE Transactions on Plasma Sci., 26(6), 1635-1644.

Sijacac, D.D.; Ebert, U. (2002). Transition from townsend to glow discharge: subcritical, mixed, or supercritical characteristics. Phy. Review., E(66), 066410-1- 06641012.

Soberon, F.; Faulkner, R.; Ellingboe, A. (2003). Plasma diffusion into a picket- fece magnetic field in ARIS (applied radio-frequency Inductive Source). (Applied Radio Frequency Inductive Source), Supported by Association Euration DCU Contract, No. ERB, 5004C, 960011.

Turner, M.M. (1993). Collisionless electron heating in an inductively coupled discharge. Phys. Rev. Lett., 71,1844-1847. 